\title{
Fostering University Students' Idea Generation and Idea Evaluation Skills With a Cognitive-Based Creativity Training
}

\author{
Kim van Broekhoven \\ Radboud University, The Netherlands \\ E-mail address: kim.vanbroekhoven@ docentenacademie.ru.nl \\ lan Hocking \\ Independent Researcher, Canterbury, United Kingdom \\ E-mail address: ihocking@gmail.com
}

\author{
Barbara Belfi \\ Maastricht University, The Netherlands \\ E-mail address: b.belfi@maastrichtuniversity.nl \\ Rolf van der Velden \\ Maastricht University, The Netherlands \\ E-mail address: r.vandervelden@maastrichtuniversity.nl
}

\section{ARTICLE INFO}

\section{Keywords:}

Cognitive-based creativity training Idea generation

Idea evaluation

Divergent thinking

Convergent thinking

\section{Article history:}

Received 16 August 2020

Received in revised form 27 November 2020

Accepted 13 December 2020

ISSN: 2354-0036

DOI: $10.2478 /$ ctra-2020-0015
A B S TRACT

This paper examines the effectiveness of a 10-hour cognitive -based creativity training on idea generation and idea evaluation among 51 undergraduate students (mean age 22) from a large university in the Netherlands. A pre-post-test withinsubject design was conducted. All 51 students received the training as part of their bachelor program, and were assigned to receive the training in the first or second semester. As such, students participated in both experimental conditions (control and intervention), albeit at different times (within-subject design). The Alternative Uses Task (AUT) and specially designed idea evaluation tasks were used before and after the training. In the idea evaluation task, students were asked to evaluate ideas on their originality and feasibility. Their ratings were compared with content experts' ratings. General Linear Models (GLM) for repeated measures were conducted to determine whether any change in idea generation and idea evaluation is the result of the interaction between type of treatment (i.e. intervention or control group) and time (pre- and post-test). The results indicated that students did not generate significantly more (i.e. fluency) and different kind of ideas (i.e. flexibility) after training. Most importantly, in line with recent research, the results suggested that training does not impact idea evaluation skills among students. This suggests that idea evaluation might be a more complex process to enhance than idea generation. The implications of these results for educational practice and future research are discussed. 


\section{INTRODUCTION}

One skill that is believed to be particularly important in the future labour market is creativity. This is because, up till now, computers are still not able to generate original and feasible ideas for complex problems, such as social, economic, and technological challenges (Autor, Levy, \& Murnane, 2003). Therefore, policy makers and business leaders around the world have stressed that creativity should be fostered among graduates (Cachia, Ferrari, Ala-Mutka, \& Punie, 2010; IBM, 2010). Research has further shown that creative thinking skills can be trained (see Scott, Leritz, \& Mumford, 2004a for a meta-analysis). However, to date, creativity training is often not an integral part educational systems; in fact, the education system often discourages it (Baepler, Walker, \& Driessen, 2014; Edwards \& McGoldrick, 2006).

Creativity can be defined as "the interaction among aptitude, process, and environment by which an individual or group produces a perceptible product that is both novel (original, new) and useful (appropriate, feasible) as defined within a social context" (Plucker, Beghetto, \& Dow, 2004, p. 90). Idea generation is a vital stage in this "interaction among aptitude, process, and environment" and depends heavily on divergent thinking capacity, that is, one's capability to generate numerous ideas (Kaufman \& Sternberg, 2019). However, also a certain level of judgment is involved in creativity: it is not only important to have many ideas, but it is also vital to know which ideas are the most original and useful. As such, comprehensive theories of creativity suggest that in addition to idea generation, also idea evaluation is a vital process in the creativity process. This stage relies predominantly on convergent thinking capacity (i.e. one's capability to recognize the most original and feasible ideas, see Cropley, 2006; Fogler, LeBlanc, \& Rizzo, 1995; Scott, Leritz, \& Mumford, 2004b). The most common view on how divergent and convergent thinking styles are related to one another is that some moderate level of convergent thinking is necessary to be able to come up with many ideas (Kaufman \& Sternberg, 2019). For example, Basadur, Runco, and Vega (2000) found that people's ability in idea generation was an important predictor for their ability to accurately recognize original ideas (i.e. idea evaluation).

The most popular way to enhance creativity has been training (Birdi, 2016; Scott et al., 2004a; Valgeirsdottir \& Onarheim, 2017). As such, many organizations have invested substantial time and resources in the development and deployment of creativity training among their staff. For example, the Community Innovation Survey (CIS) - a questionnaire developed by Eurostat to investigate organizations' innovation activities in 19 countries revealed that in $57 \%$ of firms that they deemed as 'innovative', engaged in innovation- 
related training activities (OECD, 2010). Also in higher education, creativity training - executed as either distinct course segments or workshops - has been developed for almost every student population including, for example, psychology students (Vally et al., 2019), nursing students (Liu, Wang, Chen, \& Chao, 2020), engineering students (Zhou, 2012), and business students (Ritter, Gu, Crijns, \& Biekens, 2020).

Since there is no established strategy yet regarding to how creativity can best be trained, creativity training programs come in many shapes and forms. Scott et al. (2004a), carried out a meta-analysis study to categorize creativity training programs as to whether or not they stressed (a) cognitive models, (b) social models, (c) personality models, (d) motivational models, (e) confluence models (supplemented cognitive models), or (f) other models (e.g. attitudes, blocks to creative thinking). They found that training programs that involved cognitive skills were most effective (Scott et al., 2004a). A typical cognitive-based training program focuses on various cognitive strategies for performing creative tasks, such as brainstorming or analogical thinking.

However, a limitation of many cognitive-based training programs is that they predominantly focus on training in divergent thinking and ignore convergent thinking, because they assume that convergent thinking automatically occurs within the context of creative though, which has been found to be untrue (Scott, Leritz \& Mumford, 2004b; Fasko, 2001). Therefore, Mumford, Baughman, and Sager (2003), among others, have argued that it is important to integrate both divergent and convergent thinking as principal components in cognitive-based creativity training programs. To date, there are only a few studies that have investigated the effect of a cognitive-based creativity training on divergent and convergent thinking (Basadur et al., 2000; Ritter \& Mostert, 2016; Ritter, Gu, Crijns, \& Biekens, 2020; Runco \& Basadur, 1993). The results of these studies are mixed, where some studies reported positive results, other studies did not show an improvement in convergent thinking after training (see 'past studies of cognitive-based training programs' for more information). For example, Basadur et al. (2000) found that managers recognized more accurately the originality of their ideas after a cognitive-based creativity training, wherein they experienced three stages of creativity (i.e. problem finding, idea generation and idea evaluation). In contrast, Ritter et al. (2020) found no effect of a similar cognitive-based creativity training on undergraduates' ability to recognize more accurately which ideas were creative. To shed more light on this debate, the present study designed and tested a cognitive-based creativity training for undergraduates to enhance their skills in idea generation (i.e. divergent thinking) and idea evaluation (i.e. convergent thinking). 


\section{Past studies of cognitive-based training programs}

Numerous studies have investigated whether cognitive-based training may be a viable way to enhance divergent thinking skills (e.g. Abraham et al., 2019; Castillo, 1998; Hudgins \& Edelman, 1988; Jausovec, 1994; Khatena, 1971; Ritter \& Mostert, 2016; Ritter et al., 2020; Sun et al., 2019). For instance, in the study of Khatena (1971), 188 preschool children received a 6-h training which incorporated three creative thinking techniques (i.e. breaking away from the obvious and commonplace, restructuring, and synthesis). They found that training improved performance on divergent thinking (DT) tests (specifically, on fluency, flexibility, originality, and elaboration). Similarly, in the study of Sun et al. (2019), fifty undergraduates received a demonstration of a computer-based cognitive mapping tool for applying creative thinking techniques, whereas fifty other undergraduates did not receive this demonstration. They found that the computer-based cognitive mapping tool improved students' performance on divergent thinking (DT) tests (specifically, on fluency, flexibility and originality).

However, the majority of cognitive-based training programs have only measured divergent thinking. Although important, divergent thinking is only one component of creative thinking. There have been fewer studies investigating the effect of cognitive-based training programs on divergent as well as convergent thinking (Basadur et al., 2000; Birdi, 2007; Ritter \& Mostert, 2016; Ritter et al., 2020; Runco \& Basadur, 1993). The results of studies on the effect of creativity training on convergent thinking are mixed. While some studies reported positive results, other studies did not show an improvement in convergent thinking after training.

For example, in the study of Runco and Basadur (1993), thirty-five managers attended a 20-h cognitive-based creativity training wherein they experienced three stages of creativity on managerial problems (i.e. problem finding, idea generation and idea evaluation). In the training, the participants learned to apply various creative thinking techniques (e.g. brainstorming). Before and after the training, idea generation and idea evaluation tasks were conducted to measure divergent and convergent thinking (see Runco \& Basadur, 1993 for more information). In the idea evaluation task, managers rated their own ideas on originality and their ratings were compared with the statistical infrequency of ideas to determine accuracy. The results suggested that training improved managers' ability to generate more ideas (i.e. fluency) and recognize more accurately the originality of their ideas. A subsequent study from Basadur et al. (2000) reported similar findings among 112 managers who recognized more accurately the originality of their ideas after training. 
In contrast, Ritter et al. (2020) found no effect of creativity training on undergraduates' ability to recognize more accurately which business ideas were creative (i.e. convergent thinking). In this study, hundred thirty-three undergraduates attended a 140-h cognitive-based creativity training wherein they experienced six stages of creativity on a wide range of problems (i.e. understanding the question, convergent thinking, divergent thinking, detached thinking, stop thinking and sleeping). In the training, the participants learned to apply four creative thinking techniques (i.e. simplify, differentiate, visualize, and tag the problem). Before and after the training, divergent and convergent thinking was measured. Divergent thinking was measured by a visual imagination task and the Alternative Uses Task (AUT: Guilford, 1967). Convergent thinking was measured by a convergent visual task, the Remote Associate Test (RAT: Mednick, 1962), and an idea selection task (see Ritter et al. 2020 for more information). The idea selection task is comparable to the idea evaluation task of Runco and Basadur (1993). In this task, participants had to rank order three pictures of business ideas from most creative to least creative. These business ideas had been evaluated by creativity experts as well to determine their accuracy. In line with Basadur et al. (2000) and Runco and Basadur (1993), they found that creativity training improved students' ability to generate more ideas (i.e. fluency) and their cognitive flexibility. However, in contrast, they found no effect of creativity training on any of the convergent thinking measures.

In sum, previous research has found that cognitive-based creativity training can enhance divergent thinking, but there are mixed findings concerning convergent thinking. As such, the first aim of the present study is to replicate existing findings regarding the effect of creativity training on idea generation (i.e. divergent thinking). The second aim is to contribute to the debate whether convergent thinking is a skill that can be enhanced via training. For this, we will investigate the effect of creativity training on idea evaluation (i.e. convergent thinking).

\section{Creativity techniques}

Various creativity techniques have been developed to benefit different stages in the creative process (Vernon, Hocking, \& Tyler, 2016). The techniques incorporated in the current training facilitated idea generation (i.e. silent brainstorming and analogical thinking) or idea evaluation (i.e. idea evaluation metric and strengths and weaknesses analysis). Each of these techniques is described in detail below.

Creativity techniques enabling idea generation generally employ two types of methods to facilitate the generation of ideas: (1) a stimuli-oriented method (i.e. focusing on internal or external as means to generate new ideas) and (2) a relationship-oriented meth- 
od (i.e. focusing on free association or forced relationships as means to generate new ideas). Internal or external stimuli refers to the different types of stimuli used to achieve a shift in perspective with respect to the problem to foster idea generation. In techniques employing 'internal stimuli', the problem statement itself is the main stimulus to foster the generation of new ideas. In contrast, in techniques employing 'external stimuli', objects, pictures, or concepts that are unrelated to the problem statement are used to trigger new ideas to arise. The greater the perspective shift, the more likely it is that remote elements will be formed into new combinations, and hence ideas are produced that are different from each other (Dahl \& Moreau, 2002).

Furthermore, free associations or forced relationships refers to the use of linking new perspectives to the problem to foster idea generation. In techniques that apply free association, participants follow their own train of thought and rely largely on chance and incubation. They initially generate ideas that are most accessible in memory, and, therefore, common rather than original. In contrast, forced relationships can be described as forcing together two or more different objects, products, or ideas to produce different kind of ideas. In forced relationships, students associate two unrelated concepts that results in forming remote associations (Daly, Christian, Yilmaz, Seifert, \& Gonzalez, 2012). Remote associations are more likely to produce original ideas, as they ensure that people think outside-the-box (Isaksen, Dorval, \& Treffinger, 2010).

Silent brainstorming is one of the creativity techniques in the training program that enhances idea generation. This technique employs internal stimuli and free associations as means to come up with new ideas. In this technique, a problem statement which consists of internal stimuli (i.e. important nouns and verbs) is used to generate new ideas by means of free association with the internal stimuli. In the training, the participants were first provided with an explanation of the advantages of brainstorming individually. Specifically, they were informed that brainstorming alone and in silence is more effective than traditional brainstorming, because it allows one to generate ideas without any restrictions, guidelines or distractions (i.e. free association). This technique is focused on the quantity of produced ideas and not on the number of different conceptual categories into which the ideas can be classified (Stroebe, Nijstad, \& Rietzschel, 2010). Based on the above, we hypothesized that:

H1a: Students who received creativity training will generate more ideas for divergent thinking tasks (i.e. fluency) than those who did not receive the training. Another technique that was employed in the training programs, is analogical thinking. This technique employs external stimuli and forced relationships as means to come 
up with new ideas (Gassmann \& Zeschky, 2008). In this technique, one has to associate characteristics from an external stimuli (i.e. the analogy) with characteristics of the original problem to create new ideas (Daly et al., 2012). The forced relationship means that these characteristics from an external stimuli have to be forced back to the original problem which could lead to perspective shifts. Ritter and Mostert (2016) found that the application of this technique resulted in an increase in the number of ideas that can be classified into different conceptual categories (i.e. cognitive flexibility). Based on the above, we hypothesized that:

H1b: Students who received creativity training will generate more different conceptual categories into which their ideas can be classified for divergent thinking tasks (i.e. flexibility) than those who did not receive the training.

Once a large number of ideas have been generated using one or more of the idea generation techniques, it has to be decided which solution is most promising. Several techniques have been developed to enhance idea evaluation (Vernon et al., 2016). There are hints in the literature that techniques such as metrics to classify the feasibility and originality of an idea can be helpful in identifying how feasible and original it is (Sarkar \& Chakrabarti, 2008). In addition, it has been found that a strength and weaknesses analysis enhances performance in idea evaluation accuracy (Licuanan, Dailey, \& Mumford, 2007).

An idea evaluation metric is one of the creativity techniques in the training program that enables idea evaluation (Sarkar \& Chakrabarti, 2008). In the training, participants were asked to classify all their generated ideas according to their feasibility and originality. This metric provides participants with more insights into what kind of ideas they have generated. For instance, one idea to expand businesses outside an emerging market could be "marketing". By using the metric, the idea could be put in the matrix under highly unoriginal and highly feasible. As a result, participants might realize that this idea has been mentioned a lot by other students during idea generation and, therefore, helps participants in recognizing which ideas are truly original or not. Based on the above, we hypothesized that:

\section{H2a: Students who received creativity training will become more accurate} in idea evaluation in terms of originality than those who did not receive the training (compared to experts).

The ALoU technique is one of the other creativity techniques in the training program. This is a strength and weaknesses analysis which stands for Advantages, Limitations, how to Overcome them and Unique qualities (Treffinger, 2007). For each idea, participants are instructed to think of its advantages, its limitations, how to overcome these limi- 
tations, and the unique qualities. The ALoU technique stresses idea evaluation as an inherently creative activity in which the implications of ideas must be explored: students are instructed to think of limitations for each idea. Next, they are asked to generate possible ways to overcome these limitations. An original idea that seems unfeasible and quite outlandish may, perhaps with some modifications, turn out to be very successful after all. To clarify this process, imagine that as a possible solution for the problem of exceeding the speed limit, the following idea is generated: "speed camera lottery pays drivers for slowing down". At first sight, a limitation of this idea would be that it is a costly idea and that it is unfair to use taxpayer money for this. A possible way to overcome this limitation is to come up with the idea to collect money from speeders to pay law-abiding drivers. In this way, the limitation that the idea is costly and involves taxpayer money is off the table. By exploring the implications of ideas and restructuring of ideas, it might help participants in recognizing which ideas are truly feasible or not. Based on the above, we hypothesized that:

H2b: Students who received creativity training will become more accurate in idea evaluation in terms of feasibility than those who did not receive the training (compared to experts).

\section{METHOD}

\section{Participants}

The current study was conducted from September 2017 to December 2017 at a large university in the Netherlands. In total, 51 third-year bachelor students in international business followed the creativity training entitled 'Creative Problem-Solving for Emerging Markets'. From 51 students, 24 were female and 27 were male, and the average age was 22 $(S D=1.33)$, ranging from 20 to 26 years.

The research was not of medical nature, no minor or persons with disability were involved, and there were no potential risks to the participants; therefore, ethical approval was, when data collection started, not required by the Institution's guidelines and national regulations.

\section{Procedure}

The study employed a pre-post-test within-subject design. In total, 51 undergraduates performed two treatments - a control trial and an intervention trial - which were counterbalanced and with sufficient time between trials to allow residual effects to dissipate (four weeks between trials). In the control group, students did not receive creativity training, whilst in the intervention group they received a 10-h creativity training. The same procedures were used during both semesters, which were conducted by the same experimenter and creativity trainer. 
As such, 29 students attended the training in the first educational semester and then performed in the control group in the second semester, whilst 22 students performed the control group first and attended the training in the second educational semester (see Figure 1). As such, students participated in both experimental conditions (control and intervention), albeit at different times (within-subject design).

Students' divergent and convergent thinking skills were assessed at four time points via online surveys: at the beginning of the training program in semester 1 (pre-test 1), at the end of the training program in semester 1 (post-test 1), at the beginning of the training program in semester 2 (pre-test 2), and at the end of the training program in semester 2 (post-test 2). Each online survey took approximately 30 minutes.

At each measurement occasion, divergent thinking was measured by the often used Alternative Uses Task (AUT: Guilford, 1967) and convergent thinking by specifically designed idea evaluation tasks (see 'Measures' section). For each semester, the pre- and post-measures were the same. To prevent fatigue effects among students, the second educational semester employed equivalent versions of the tasks used in semester 1 (i.e. the versions did not differ in the types of question nor in levels of difficulty).

Semester 1
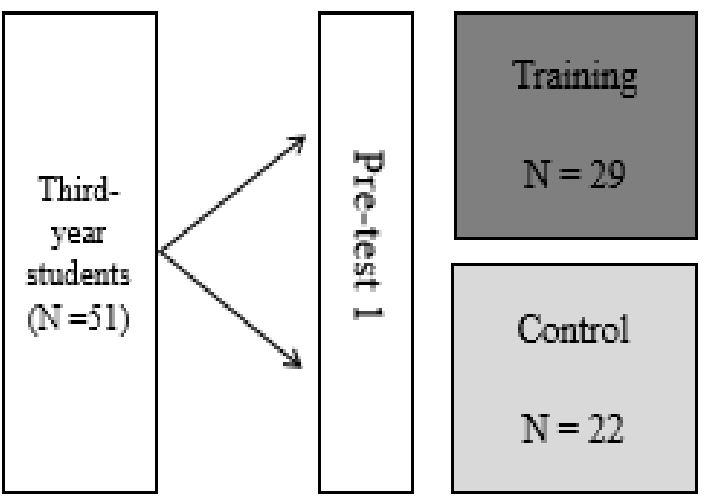

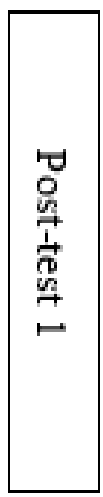

Semester 2
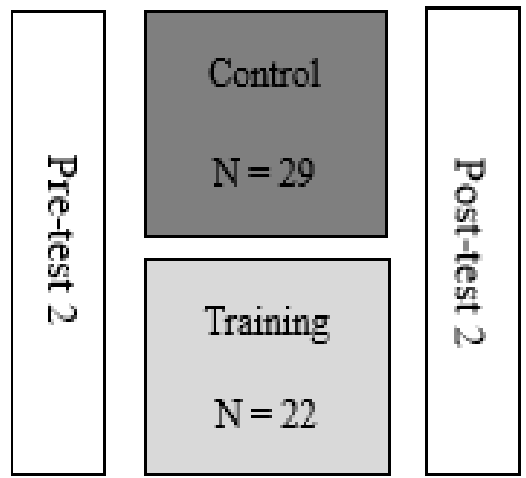

Figure 1. Experimental design: pre-post-test within-subject design

\section{Creativity training}

The creativity training program is provided as a mandatory course for third-year bachelor students in business and economics at a major Dutch university. The creativity course (in total 10 hours) contained five weekly two-hour sessions. The course entailed an opening lecture (i.e. focus on theory) and training sessions (i.e. focuses on practice exercises in which students apply techniques on problems in the field of international business).

In the creativity training, students learned to apply four stages of creative problem solving to a wide range of problems. The four stages - problem definition, idea generation, idea evaluation, and idea implementation - are described in more detail below. 
(1) Problem definition. Students received ill-defined problems in the field of international business. III-defined problems are often characterised by multiple goals, requiring diverse avenues of exploration that highlight a range of possible solutions (Reiter-Palmon \& Illies, 2004). As such, students acquired knowledge to define the problem correctly.

(2) Idea generation. This stage is often associated with divergent thinking. Divergent thinking involves producing multiple or alternative answers to an open-ended problem (Guilford, 1959). As such, students were asked to generate different kinds of alternatives instead of focusing on one idea or solution.

(3) Idea evaluation. This stage is often associated with convergent thinking. In contrast to divergent thinking, convergent thinking can be defined as a more strongly constrained process that searches for one possible outcome for a given problem (Hommel, Colzato, Fischer, \& Christoffels, 2011). In idea evaluation, ides are checked against criteria for the task and criteria in the domain more generally, to ensure the usefulness or appropriateness of the novel ideas emerging from the idea generation stage (Lonergan, Scott, \& Mumford, 2004).

(4) Idea implementation. In this stage, decisions are made based on the results of the idea evaluation stage.

Four creativity techniques were provided to facilitate the four stages of creative problem solving: silent brainstorming, analogical thinking, idea evaluation metric, and ALoU (see 'Training techniques' section). In the training, students are asked to solve an ill -defined problem in the field of international business. In each of the training session, they are repeatedly provided with different types of example problems, which trigger them to practice the different stages of creative problem solving. Each training session started with explanation and illustration of a creativity technique. After the explanation, students participated in a warming-up or energizer: a short group activity that is not aimed at developing creativity, but at energizing the students. The warming-up prepares the mind for the theory and training provided.

\section{MEASURES}

A number of measures were used to assess baseline performance and improvement in idea generation and idea evaluation. These measures were administered before and after the creativity training.

\section{Idea generation}

Idea generation was assessed by the Alternative Uses Task (AUT: Guilford, 1967). This divergent thinking task is widely used to evaluate creative thinking ability and the effectiveness of creativity training (Acar \& Runco, 2012; Dyson et al., 2016). In this task, individuals are asked to list as many different and unusual uses for common household ob- 
jects as possible in two minutes. In the first semester, these objects were a brick and an umbrella, and in the second semester a newspaper and a paper clip (both pre- and posttest). The objects were counterbalanced in each semester.

The total number of non-redundant ideas (i.e. fluency) and the total number of different conceptual categories into which ideas can be classified (i.e. flexibility) were measured for the AUT ${ }^{1}$. To measure flexibility, two independent raters, who were not informed of the conditions, classified each idea according to a predefined list of idea categories (see Tables in the Online Supplementary Material). Next, the total number of distinct idea categories is calculated. The interrater reliability of the ratings was calculated using a two -way random ICC analysis for consistency and can be considered excellent (ICC $\mathrm{brick}_{\text {. }}$ $\left.=.92, \mathrm{ICC}_{\text {umbrella }}=.90, \mathrm{ICC}_{\text {newspaper }}=.88, \mathrm{ICC}_{\text {paper clip }}=.90\right)$.

\section{Idea evaluation accuracy}

To objectively measure participants' ability to evaluate ideas, a domain-specific idea evaluation task was developed. Prior to our experiment, 33 students from the previous cohort were asked to individually generate ideas for two similar problems: 'What can government in emerging markets do to attract new business from abroad?' and 'What can companies in emerging markets do to expand their business outside their own countries?' This resulted in respectively 285 and 227 ideas. These were further reduced to a list of 71 and 76 ideas by removing duplicates and collapsing ideas that were similar (i.e., 'improve language proficiency' and 'learn languages' were collapsed into one idea, 'learn the language').

These ideas were then rated by three experts. The experts are professionals that have worked in a private organization or government in an emerging market on similar issues as the problem in question ${ }^{2}$. As such, these experts had considerably more experience in the domain than students. The experts were asked to rate each idea on originality and feasibility using a Likert scale ranging from 1 (not at all original/feasible) to 5 (very original/feasible).

After their evaluation, a set of ten ideas was selected for semester 1 . To prevent fatigue effects, another set of ideas was selected for semester 2 in which five ideas remained the same as in semester 1 (see Online Supplementary Material). The sets of ideas were selected based on (a) sufficient variation in the novelty/usefulness evaluations and (b) sufficient high inter-rater reliability. The overall intraclass correlation coefficient

\footnotetext{
${ }^{1}$ The originality of ideas is not measured, because the main goal of the study was to replicate existing findings regarding the effect of creativity training on divergent thinking and the measures fluency and cognitive flexibility are considered to be sufficient. Moreover, the total number of ideas (3,748 ideas) was so large, that it would have been impossible for raters to process.

${ }^{2}$ For instance, one expert has worked in an organization that offers support and advice to public-private partnerships in the health sector in emerging countries (i.e. Nigeria and Tanzania). Another expert has worked at the Thai government developing policies to attract new business from abroad such as tax subsidy system, visit trade shows, the establishment of an organization to help foreign investors.
} 
(ICC, two-way random, consistency analysis) was .75 for semester 1 and .74 for semester 2, and the single interrater reliability were good as well (feasibility ICC semester $1=.85$;

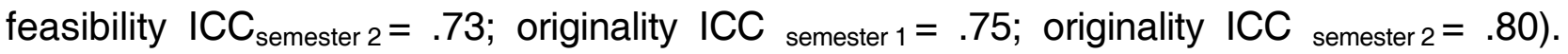
In each measurement, students received these set of ideas for the two problems.

Students first evaluated ideas in terms of originality, i.e. the degree to which an idea is unique or novel (Putman \& Paulus, 2009; Rietzschel, Nijstad, \& Stroebe, 2010). Second, students evaluated ideas in terms of feasibility, i.e. the degree to which an idea is practical or realistic (Kim, Chung, \& Yu, 2013; Reiter-Palmon, Mumford, O'Connor Boes, \& Runco, 1997). Students used a Likert scale ranging from 1 (not at all original/feasible) to 5 (very original/feasible).

Idea evaluation accuracy was measured by comparing student's evaluations with those of experts. As described earlier, experts evaluated each individual idea for originality and feasibility using the same Likert scale as was used by the students. By averaging the scores of the three experts, each idea received an originality and feasibility score. For each idea, the value of the participants' evaluations was substracted from the average value of the expert's evaluation for that respective idea, separately for originality and feasibility. These differences were then turned into absolute differences so that larger differences reflected less accurate evaluations by the participants, regardless of direction. To easily interpret training effects, these values were reversed so that higher values indicated a more accurate evaluation. As such, idea evaluation accuracy can be seen as the degree of concordance between students and experts.

\section{RESULTS}

The means and standard deviations for each measure at pre- and post-test for the two groups are shown in Table 1. Three participants did not complete the divergent thinking tasks, and, therefore, the performance of 48 participants could be analysed on the divergent thinking task.

\section{Table 1}

Means and standard deviations for each measure at pre-and post-test

Idea generation $(\mathrm{N}=48)$

Fluency $\quad$ Flexibility
Idea evaluation $(\mathrm{N}=51)$

Accuracy in originality Accuracy in feasibility

\begin{tabular}{llcccccccc} 
& & Pretest & Post-test & Pretest & Post-test & Pretest & Post-test & Pretest & Post-test \\
\hline \multirow{2}{*}{ Intervention } & Mean & 5.77 & 6.42 & 4.63 & 5.14 & 2.75 & 2.79 & 2.61 & 2.57 \\
& $S D$ & $(2.44)$ & $(2.61)$ & $(1.88)$ & $(1.78)$ & $(0.23)$ & $(0.21)$ & $(0.30)$ & $(0.29)$ \\
\multirow{2}{*}{ Control } & Mean & 5.97 & 6.14 & 4.88 & 5.00 & 2.82 & 2.81 & 2.70 & 2.62 \\
& $S D$ & $(2.27)$ & $(2.45)$ & $(1.55)$ & $(1.76)$ & $(0.18)$ & $(0.22)$ & $(0.25)$ & $(0.29)$ \\
\hline
\end{tabular}


A General Linear Model (GLM) for repeated measures was conducted to determine whether any change in idea generation and idea evaluation is the result of the interaction between type of treatment (i.e. intervention or control trial) and time (pre- and post-test). For each dependent variable, a separate GLM for repeated measures was conducted with treatment and time as independent variables (see Table 2).

Table 2

Test of within subject effect using General Linear Model (GLM) for repeated measures

Test of within subject effect on idea generation: fluency

\begin{tabular}{|c|c|c|c|c|c|c|c|}
\hline Source & $\begin{array}{c}\text { Sum of } \\
\text { squares }\end{array}$ & $d f$ & Mean square & $F$ value & & $p$ value & partial $\eta^{2}$ \\
\hline Time & 7.922 & 1 & 7.922 & 3.811 & * & .057 & .075 \\
\hline Treatment & .083 & 1 & .083 & .026 & & .872 & .001 \\
\hline Time $\mathrm{x}$ Treatment & 2.755 & 1 & 2.755 & 1.344 & & .252 & .028 \\
\hline Error & 96.37 & 47 & 2.05 & & & & \\
\hline
\end{tabular}

Test of within subject effect on idea generation: flexibility

\begin{tabular}{|c|c|c|c|c|c|c|c|}
\hline Source & $\begin{array}{c}\text { Sum of } \\
\text { squares }\end{array}$ & $d f$ & Mean square & $F$ value & & $p$ value & partial $\eta^{2}$ \\
\hline Time & 4.845 & 1 & 4.845 & 4.105 & * & .048 & .080 \\
\hline Treatment & .158 & 1 & .158 & .103 & & .749 & .002 \\
\hline Time $\mathrm{x}$ Treatment & 1.783 & 1 & 1.783 & 1.709 & & .198 & .035 \\
\hline Error & 49.030 & 47 & 1.043 & & & & \\
\hline \multicolumn{8}{|c|}{ Test of within subject effect on idea evaluation: accuracy in originality } \\
\hline Source & $\begin{array}{l}\text { Sum of } \\
\text { squares }\end{array}$ & $d f$ & Mean square & $F$ value & & $p$ value & partial $\eta^{2}$ \\
\hline Time & .019 & 1 & .019 & .927 & & .340 & .018 \\
\hline Treatment & .089 & 1 & .089 & 1.910 & & .173 & .037 \\
\hline Time $\mathrm{x}$ Treatment & .040 & 1 & .040 & 1.270 & & .265 & .025 \\
\hline Error & 1.581 & 50 & .032 & & & & \\
\hline
\end{tabular}


Test of within subject effect on idea evaluation: accuracy in feasibility

\begin{tabular}{|c|c|c|c|c|c|c|c|}
\hline Source & $\begin{array}{l}\text { Sum of } \\
\text { squares }\end{array}$ & $d f$ & Mean square & $F$ value & & $p$ value & partial $\eta^{2}$ \\
\hline Time & .193 & 1 & .193 & 9.938 & 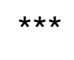 & .003 & .166 \\
\hline Treatment & .246 & 1 & .246 & 1.596 & & .212 & .031 \\
\hline Time $\mathrm{x}$ Treatment & .028 & 1 & .028 & .875 & & .354 & .017 \\
\hline Error & 1.571 & 50 & .031 & & & & \\
\hline
\end{tabular}

Note: The large effects of time can be explained by the identical tasks in the pre-and posttest (for each semester). In order to rule out learning effects (i.e. increase in fluency and flexibility due to learning on the task rather than learning due to the training), we tested whether the increase in fluency and flexibility for the intervention group was larger than the increase in fluency and flexibility for the control group. As expected, we found that the intervention group reported a significant larger increase on fluency and flexibility than the control group. Both groups are expected to report increases on fluency and flexibility, but the intervention group reported a significantly larger increases due to training. Significance levels indicated as follows: ${ }^{\star} p<.10,{ }^{\star \star} p<.05,{ }^{\star \star \star} p<.01$.

\section{Idea generation}

It was firstly hypothesized that creativity training would enhance the total number of generated ideas (i.e. fluency) (H1a). As shown in Table 1, students with training reported a higher level of fluency after training $(M=6.42, S D=2.61)$ than students without training $(M=6.14, S D=2.45)$. The General Linear Model $(G L M)$ for repeated measures on fluency indicated a significant main effect of time, $F(1,47)=3.811, p<.10$, partial $\eta^{2}=.075$ (see Table 2). This indicates that students were better at post-test than pre-test. However, neither the main effect of treatment $(F(1,47)=.026, p>.10)$ nor the interaction of time with treatment were found to be significant $(F(1,47)=1.344, p>.10)$. As such, hypothesis 1a was not supported.

Secondly, it was hypothesized that creativity training would enhance the number of different conceptual categories into which ideas can be classified (i.e. flexibility) (H1b). An inspection of the mean scores (Table 1) shows that students with training reported a higher level of flexibility after training $(M=5.14, S D=1.78)$ than students without training $(M=5.00, S D=1.76)$. The General Linear Model $(G L M)$ for repeated measures on flexibility indicated a significant main effect of time, $F(1,47)=4.105, p<.10$, partial $\eta^{2}=.080$ (see Table 2). This means that students were better at post-test than pre-test. However, neither the main effect of treatment $(F(1,47)=.103, p>.10)$ nor the interaction of time with treatment were found to be significant $(F(1,47)=1.709, p>.10)$. As such, hypothesis $1 b$ was not supported.

Hence, we found that students were better in idea generation at the post-test than pre-test (see Figure 2). However, the interaction of time and treatment did not reach sig- 
nificance, and, therefore, we cannot conclude that training significantly improved idea generation skills among students.

\section{FLUENCY}

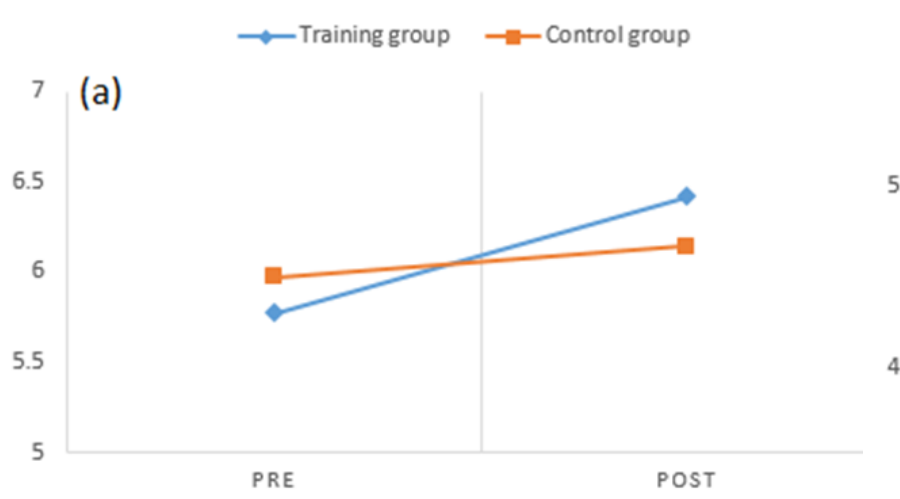

\section{FLEXIBILITY}

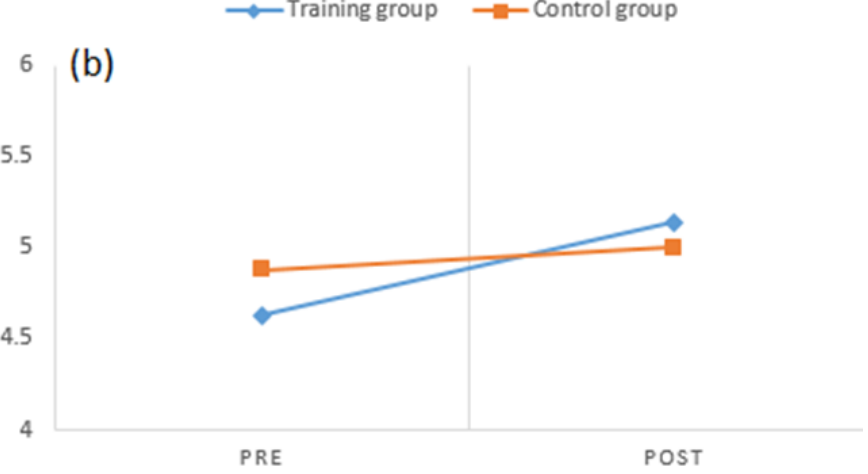

Figure 2. Interactions between treatment and time on idea generation

Note: The graphs reports estimates of the General Linear Model (GLM) for repeated measures. It shows the mean fluency and flexibility scores in the pre and post-test per experimental group (scale range is $+1 / 2$ SD and $-1 / 2$ SD from the average).

\section{Idea evaluation}

For idea evaluation accuracy, we first hypothesized that students would become more accurate in their evaluation of original ideas after training $(\mathrm{H} 2 \mathrm{a})$. An inspection of the mean scores (Table 1) shows that students without training recognised more accurately which ideas were original $(M=2.81, S D=.22)$ than students with training $(M=2.79, S D$ $=.21$ ). However, the General Linear Model (GLM) for repeated measures did not find a significant interaction of time with treatment, $F(1,50)=1.271, p>.10$ (see Table 2). Hence, hypothesis 2 a was not supported.

Secondly, it was hypothesized that students would become more accurate in their evaluation of feasible ideas after training ( $\mathrm{H} 2 \mathrm{~b})$. An inspection of the mean scores (Table 1) suggests that students without training recognised more accurately which ideas were feasible $(M=2.62, S D=.29)$ than students with training $(M=2.57, S D=.29)$. However, the General Linear Model (GLM) for repeated measures did not find a significant interaction of time with treatment, $F(1,50)=.875, p>.10$ (see Table 2). Hence, hypothesis $2 b$ was not supported. Interestingly, there was a strong significant main effect of time, $F(1,50)=9.938, p<.01$, partial $\eta^{2}=.166$ (see Table 2). This means that students were significantly better at post-test than pre-test.

Hence, the results suggest that creativity training did not improve idea evaluation accuracy (see Figure 3). 

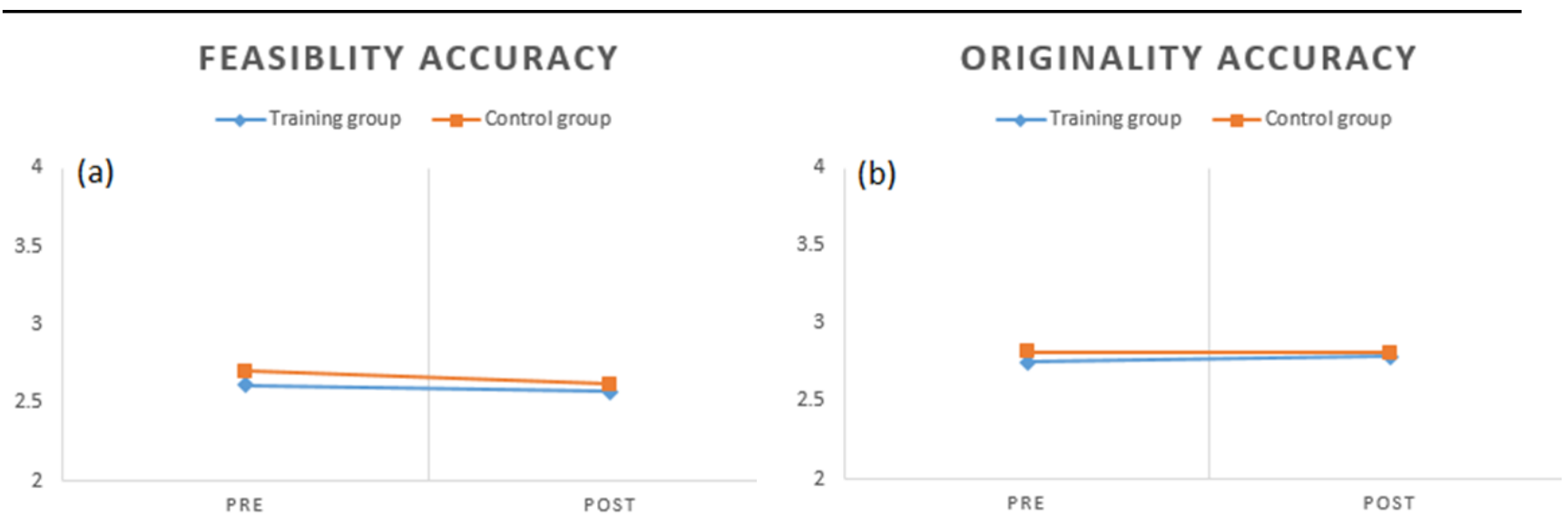

Figure 3. Interactions between treatment and time on idea evaluation

Note: The graphs reports estimates of the General Linear Model (GLM) for repeated measures. It shows the mean fluency and flexibility scores in the pre and post-test per experimental group (scale range is $+1 / 2$ SD and $-1 / 2$ SD from the average).

\section{DISCUSSION}

There is a growing consensus that education should cultivate the creative thinking skills of students to help them succeed in modern, globalised economies based on knowledge and innovation (Cachia et al., 2010; Lucas, Claxton, \& Spencer, 2013). For example, in the Programme for International Student Assessment (PISA) from the OECD, students' creative thinking skills will be assessed from 2021 onwards, in addition to the existing tests in math, language, and science. This underscores the increased importance to give more attention to the development of creative thinking skills, such as idea generation and idea evaluation.

The main goal of the current study was to examine whether a cognitive-based creativity training enhances students' idea generation and idea evaluation skills. In line with previous research, the results suggest that students generated more ideas (i.e. fluency) and more different kind of ideas (i.e. flexibility) after training, but not significant. One possible explanation for this non-significant finding might be due to the small sample size $(\mathrm{N}=48)$. Another possible explanation might be that post-test measures in other studies were more similar to the training context (Byrge \& Hansen, 2013; Im, Hokanson, \& Johnson, 2015). For example, in Im et al. (2015) participants were asked to develop lists of alternative uses for common objects during the training, and were asked to do the same in the post-test measures. Similarly, in Byrge and Hansen (2013), participants were asked to take an item from an item box (box with many different items, such as a watch, a spoon, a tissue etc.). Next, they were asked to generate as many ideas as they could on how to improve someone else's item using their own item. Both of these creativity exercises are rather similar to the Alternative Uses Task (AUT). As such, students in previous studies were more trained to the criterion (Scott et al., 2004a). 
In order to move from creativity to innovation, it is of vital importance to recognize whether the generated ideas have creative potential. Therefore, we also examined whether the training improves students' ability to recognize original and feasible ideas of others (i.e. the two components of creative ideas). In the idea evaluation tasks, participant had to rate business ideas on their originality and feasibility, and their ratings were compared with those of experts to determine accuracy. The results of this study suggest that creativity training had no effect on participants' idea evaluation performance. This finding is in line with Ritter et al. (2020) who also found no significant effect of training on participants' idea selection performance. As such, the results suggest that idea evaluation techniques, such as the idea evaluation metric and the ALoU technique do not improve idea evaluation accuracy. Research has suggested that knowledge plays a critical role in the convergent thinking process, as it is a source of ideas, and provides the knowledge necessary for assessing novelty and feasibility of ideas (Cropley, 2006). As such, a possible explanation for the fact that idea evaluation techniques do not seem to work is because these techniques are general and not focused on building up knowledge and expertise.

\section{Limitations and future research}

Several limitations of the present study should be noted. Firstly, the creativity trainer was also the experimenter of the study. As such, the 'Clever Hans' phenomenon in which the experimenter's hypothesis is unintentionally communicated to the participants might have happened in this study (Johnson, 1911). However, this would have only affected idea generation and not idea evaluation. The experimenter's hypothesis was rather predictable with idea generation (better performance in idea generation tasks), but more difficult to define for idea evaluation since idea evaluation accuracy is highly dependent on domain knowledge (the experimenter does not know when an idea is truly feasible or original according to the experts). Nonetheless, we would still recommend for future research that the creativity trainer would be someone else than the experimenter of the study.

The second limitation relates to external validity issues. Like Ritter et al. (2020), the current study has been conducted among international business students. Even though students are often used as a research population, the population of international business students is rather specific. As such, the results cannot easily be generalized to other student populations (e.g. medicine or law). Future research should investigate the effect of creativity training on idea generation and idea evaluation on other student populations as well. Related to this, students have only been asked to generate ideas for one divergent thinking task (i.e. the Alternative Uses Task). As such, it is unknown whether the training effects can be generalised to other divergent thinking tasks (e.g., consequences task). 
Even though the main contribution of the current study was to investigate the effect of creativity training on convergent thinking, future research should use multiple measures of divergent thinking to ensure the external validity of the results.

Furthermore, the length of training is positively related to creativity training effectiveness (e.g. Mathisen \& Bronnick, 2009; Scott et al., 2004). Mathisen and Bronnick (2009) found, for example, evidence for the effectiveness of both a 1-day and a 5-day training course. Still, they found their 5-day training to induce stronger effects. The current creativity training consists of only 10 hours of explicit training and this might be one of the reasons why the training appears to be unsuccessful. However, a recent study evaluated a 140 hours training on convergent thinking and also found no improvements in convergent thinking (Ritter et al., 2020). As such, simply increasing the length of a training may not be sufficient to enhance performance in convergent thinking. Next to training, there are a number of other approaches that have been proven to be successful in enhancing idea evaluation skills, such as task familiarity, mood, personality, regulatory focus, culture, and gender (e.g. Berg, 2016; Förster, 2009; Herman \& Reiter-Palmon, 2011; Kaufman, Niu, Sexton, \& Cole, 2010; McCarthy, Chen, \& McNamee, 2018). For instance, Basadur et al. (2000) found that people who had a natural tendency to avoid premature convergence a trait related to openness - performed better in idea evaluation tasks than people without this tendency. As such, future research, dedicated to evaluation skills, should take a step further in testing training programs with other theoretical foundations, such as a personality or social interactional model instead of a purely cognitive-based training.

Finally, this study has conducted General Linear Models (GLM) for repeated measures as a means to compare students who received the creativity training (intervention group) with those who did not (control group). The repeated measures nature of this study allowed us to compare the intervention group in semester 1 with a control group. However, since our training was offered to all students (for ethical reasons), there was no suitable comparison group that could participate in the long-term follow-up (i.e. semester 2). Therefore, the students who received the training in the second semester were compared with the students who had received the training earlier during the first semester. This might have been a reason why no effect of the creativity training on idea generation (divergent thinking) and idea evaluation (convergent thinking) could be found. However, the idea behind this was that the effect of training would be stronger visible immediately after the training, and would diminish after four weeks. We indeed found that the intervention group in semester 1 (who served as control group in semester 2) reported lower levels of fluency $(M=5.95, S D=2.56)$ and flexibility $(M=4.79, S D=1.81)$ after 
four weeks of no training than immediately after training (fluency: $M=6.21, S D=2.59$; flexibility: $M=4.97, S D=1.78)$. This decline in creativity scores is in line with a recent study that indicated that four weeks may be sufficient to let training effects diminish (Meinel, Wagner, Baccarella, \& Voigt, 2019). As such, it could be very well that the participants who attended the training in the first semester were indeed a valid control group for the students receiving the training in the second semester. Nonetheless, we would still recommend for future research to add an extra control group consisting of a random sample of comparable students who have not attended the training.

\section{Practical implications}

The current study has provided insight into how a cognitive-based creativity training is not successful in strengthening idea evaluation skills. This is an important insight, because many cognitive-based training programs assume that convergent thinking skills, such as idea evaluation, are naturally developed in the training programs. However, in line with previous research, we show that convergent thinking skills are not naturally developed within the context of a cognitive-based training.

As such, our key contribution is showing that a cognitive-based creativity training does not affect the evaluation accuracy of novel and feasible ideas, and, therefore, idea evaluation seems to be a more complex process to enhance than idea generation. However, spotting the novelty and feasibility is a crucial step in getting people to pay attention to the ideas already generated. Without it, ideas will not be captured and developed to add value in solving problems. Institutions who would like to or already have implemented cognitive-based creativity training should be aware of that such a training does not automatically foster convergent or critical thinking among students. As indicated earlier, a number of other approaches have been proven to be successful in enhancing idea evaluation skills, such as task familiarity, mood, personality, regulatory focus, culture, and gender (e.g. Berg, 2016; Förster, 2009; Herman \& Reiter-Palmon, 2011; Kaufman, Niu, Sexton, \& Cole, 2010; McCarthy, Chen, \& McNamee, 2018). As such, it might be that training programs with other theoretical foundations, such as personality or social interactional model may be more successful in enhancing convergent thinking skills.

\section{REFERENCES}

Abraham, A., Asquith, S., Ahmed, H., \& Bourisly, A. K. (2019). Comparing the efficacy of four brief inductions in boosting short-term creativity. Journal of Cognitive Enhancement, 3(1), 85-93.

Acar, S., \& Runco, M. A. (2012). Creative abilities: Divergent thinking. In Handbook of organizational creativity (pp. 115-139): Elsevier. 
Autor, D. H., Levy, F., \& Murnane, R. J. (2003). The skill content of recent technological change: An empirical exploration. The Quarterly journal of economics, 118(4), 1279-1333

Baepler, P., Walker, J., \& Driessen, M. (2014). It's not about seat time: Blending, flipping, and efficiency in active learning classrooms. Computers \& Education, 78, 227-236.

Basadur, M., Runco, M. A., \& Vega, L. A. (2000). Understanding how creative thinking skills, attitudes and behaviors work together: A causal process model. The Journal of Creative Behavior, 34(2), 77-100.

Berg, J. M. (2016). Balancing on the creative highwire: Forecasting the success of novel ideas in organizations. Administrative Science Quarterly, 61(3), 433-468. doi:10.1177/0001839216642211

Birdi, K. (2007). A lighthouse in the desert? Evaluating the effects of creativity training on employee innovation. Journal of Creative Behavior, 41(4), 249-270.

Birdi, K. (2016). Creativity training. In Human resource management, innovation and performance (pp. 298-312): Springer.

Byrge, C., \& Hansen, S. (2013). Course in new thinking in higher education: Enhancing creativity through the means of training, theory and workshop. Problems of Education in the 21st Century, 51(51), 18-32.

Cachia, R., Ferrari, A., Ala-Mutka, K., \& Punie, Y. (2010). Creative learning and innovative teaching. Retrieved from Luxembourg: Publications Office of the European Union.

Castillo, L. C. (1998). The effect of analogy instruction on young children's metaphor comprehension. Roeper Review, 21(1), 27-31.

Cropley, A. (2006). In praise of convergent thinking. Creativity Research Journal, 18(3), 391-404.

Dahl, D. W., \& Moreau, P. (2002). The influence and value of analogical thinking during new product ideation. Journal of Marketing Research, 39(1), 47-60.

Daly, S. R., Christian, J. L., Yilmaz, S., Seifert, C. M., \& Gonzalez, R. (2012). Assessing design heuristics for idea generation in an introductory engineering course. International Journal of Engineering Education, 28(2), 463.

Dyson, S. B., Chang, Y.-L., Chen, H.-C., Hsiung, H.-Y., Tseng, C.-C., \& Chang, J.-H. (2016). The effect of tabletop role-playing games on the creative potential and emotional creativity of Taiwanese college students. Thinking Skills and Creativity, 19, 88-96.

Edwards, M., \& McGoldrick, C. (2006). Creativity and curricula in higher education: academics' perspectives. In Developing creativity in higher education (pp. 79-93): Routledge.

Fogler, H. S., LeBlanc, S. E., \& Rizzo, B. R. (1995). Strategies for creative problem solving: PTR Prentice Hall Englewood Cliffs, NJ. 
Förster, J. (2009). Cognitive consequences of novelty and familiarity: How mere exposure influences level of construal. Journal of Experimental Social Psychology, 45(2), 444-447.

Gassmann, O., \& Zeschky, M. (2008). Opening up the solution space: the role of analogical thinking for breakthrough product innovation. Creativity and Innovation Management, 17(2), 97-106.

Guilford, J. P. (1959). Three faces of intellect. American Psychologist, 14(8), 469-479. doi:10.1037/h0046827

Guilford, J. P. (1967). The nature of human intelligence. New York, NY: McGraw-Hill Herman, A., \& Reiter-Palmon, R. (2011). The effect of regulatory focus on idea generation and idea evaluation. Psychology of Aesthetics, Creativity, and the Arts, 5(1), 1320. doi:10.1037/a0018587

Hommel, B., Colzato, L. S., Fischer, R., \& Christoffels, I. (2011). Bilingualism and creativity: Benefits in convergent thinking come with losses in divergent thinking. Frontiers in Psychology, 2, 273.

IBM. (2010). Capitalizing on complexity: Insights from the global chief executive officer study: IBM.

Illies, J. J., \& REITER-PALMON, R. (2004). The effects of type and level of personal involvement on information search and problem Solving 1. Journal of Applied Social Psychology, 34(8), 1709-1729.

Im, H., Hokanson, B., \& Johnson, K. K. P. (2015). Teaching creative thinking skills: A longitudinal study. Clothing and Textiles Research Journal, 33(2), 129-142.

Isaksen, S. G., Dorval, K. B., \& Treffinger, D. J. (2010). Creative approaches to problem solving: A framework for innovation and change. California, CA: Sage Publications.

Johnson, H. M. (1911). Clever hans (the horse of mr. von osten): A contribution to experimental, animal, and human psychology. The Journal of Philosophy, Psychology and Scientific Methods, 8(24), 663-666.

Kaufman, J. C., Niu, W., Sexton, J. D., \& Cole, J. C. (2010). In the eye of the beholder: Differences across ethnicity and gender in evaluating creative work. Journal of Applied Social Psychology, 40(2), 496-511.

Kaufman, J. C., \& Sternberg, R. J. (2019). Cambridge handbook of creativity. New York, NY: Cambridge University Press.

Khatena, J. (1971). Teaching disadvantaged preschool children to think creatively with pictures. Journal of Educational Psychology, 62(5), 384.

Kim, S., Chung, K., \& Yu, H. (2013). Enhancing digital fluency through a training program for creative problem solving using computer programming. The Journal of Creative Behavior, 47(3), 171-199. 
Licuanan, B. F., Dailey, L. R., \& Mumford, M. D. (2007). Idea evaluation: Error in evaluating highly original ideas. The Journal of Creative Behavior, 41(1), 1-27.

Liu, H.-Y., Wang, I.-T., Chen, N.-H., \& Chao, C.-Y. J. N. e. t. (2020). Effect of creativity training on teaching for creativity for nursing faculty in Taiwan: A quasi-experimental study. Nurse Education Today, 85, 104231.

Lonergan, D. C., Scott, G. M., \& Mumford, M. D. (2004). Evaluative aspects of creative thought: Effects of appraisal and revision standards. Creativity Research Journal, 16 (2-3), 231-246.

Lucas, B., Claxton, G., \& Spencer, E. (2013). Progression in student creativity in school. First steps towards new forms of formative assessments. Paris: OECD.

Mathisen, G. E., \& Bronnick, K. S. (2009). Creative self-efficacy: An intervention study. International Journal of Educational Research, 48(1), 21-29. doi:10.1016/j.jjer.2009.02.009

McCarthy, M., Chen, C. C., \& McNamee, R. C. (2018). Novelty and Usefulness TradeOff: Cultural Cognitive Differences and Creative Idea Evaluation. Journal of CrossCultural Psychology, 49(2), 171-198.

Mednick, S. (1962). The associative basis of the creative process. Psychological Review, 69(3), 220.

Meinel, M., Wagner, T. F., Baccarella, C. V., \& Voigt, K. I. (2019). Exploring the effects of creativity training on creative performance and creative self-efficacy: Evidence from a longitudinal study. The Journal of Creative Behavior, 53(4), 546-558.

Mumford, M. D., Baughman, W. A., \& Sager, C. E. (2003). Picking the right material: Cognitive processing skills and their role in creative thought. In M. A. Runco (Ed.), Critical and creative thinking (pp. 19-68). Cresskill, NJ: Hampton.

OECD. (2010). Measuring Innovation: A New Perspective. Paris: OECD. https:// www.oecd.org/site/innovationstrategy/measuringinnovationanewperspectiveonlineversion.htm

Plucker, J. A., Beghetto, R. A., \& Dow, G. T. (2004). Why isn't creativity more important to educational psychologists? Potentials, pitfalls, and future directions in creativity research. Educational Psychologist, 39(2), 83-96.

Putman, V. L., \& Paulus, P. B. (2009). Brainstorming, brainstorming rules and decision making. The Journal of Creative Behavior, 43(1), 29-40. doi:10.1002/j.21626057.2009.tb01304.x

Reiter-Palmon, Mumford, M. D., O'Connor Boes, J., \& Runco, M. A. (1997). Problem construction and creativity: The role of ability, cue consistency, and active processing. Creativity Research Journal, 10(1), 9-23. doi:10.1207/s15326934crj1001_2 
Rietzschel, Nijstad, B. A., \& Stroebe, W. (2010). The selection of creative ideas after individual idea generation: Choosing between creativity and impact. British Journal of Psychology, 101(1), 47-68. doi:10.1348/000712609X414204

Ritter, \& Mostert, N. (2016). Enhancement of creative thinking skills using a cognitivebased creativity training. Journal of Cognitive Enhancement, 1(3), 243-253. doi:10.1007/s41465-016-0002-3

Ritter, S. M., Gu, X., Crijns, M., \& Biekens, P. (2020). Fostering students' creative thinking skills by means of a one-year creativity training program. PloS One, 15(3), e0229773.

Runco, M. A., \& Basadur, M. (1993). Assessing ideational and evaluative skills and creative styles and attitudes. Creativity and Innovation Management, 2(3), 166-173.

Sarkar, P., \& Chakrabarti, A. (2008). The effect of representation of triggers on design outcomes. Artificial Intelligence for Engineering Design, Analysis and Manufacturing, 22(2), 101-116.

Scott, G., Leritz, L. E., \& Mumford, M. D. (2004a). The effectiveness of creativity training: A quantitative review. Creativity Research Journal, 16(4), 361-388. doi:10.1080/10400410409534549

Scott, G., Leritz, L. E., \& Mumford, M. D. (2004b). Types of creativity training: Approaches and their effectiveness. Journal of Creative Behavior, 38(3), 149-179.

Stroebe, W., Nijstad, B. A., \& Rietzschel, E. F. (2010). Beyond productivity loss in brainstorming groups: The evolution of a question. In Advances in Experimental Social Psychology (Vol. 43, pp. 157-203): Elsevier.

Sun, M., Wang, M., \& Wegerif, R. (2019). Using computer-based cognitive mapping to improve students' divergent thinking for creativity development. British Journal of Educational Technology, 50(5), 2217-2233.

Treffinger, D. J. (2007). Creative Problem Solving (CPS): Powerful tools for managing change and developing talent. Gifted and Talented International, 22(2), 8-18.

Valgeirsdottir, D., \& Onarheim, B. (2017). Studying creativity training programs: A methodological analysis. Creativity and Innovation Management, 26(4), 430-439.

Vally, Z., Salloum, L., AIQedra, D., El Shazly, S., Albloshi, M., Alsheraifi, S., \& Alkaabi, A. (2019). Examining the effects of creativity training on creative production, creative self -efficacy, and neuro-executive functioning. Thinking Skills and Creativity, 31, 70-78.

Vernon, D., Hocking, I., \& Tyler, T. C. (2016). An evidence-based review of creative problem solving tools. Human Resource Development Review, 15(2), 230-259. doi:10.1177/1534484316641512 
Zhou, C. (2012). Integrating creativity training into problem and project-based learning curriculum in engineering education. European Journal of Engineering Education, 37(5), 488-499.

\section{APPENINDIX}

\section{Online Supplementary Material}

\section{Semester 1.}

Ideas for 'what can government in emerging markets do to attract new business from abroad?'

\begin{tabular}{|c|c|c|c|}
\hline \multicolumn{2}{|r|}{ High } & - Visit trade fairs & $\begin{array}{l}\text { - Attracting talents early on (e.g. during studies) } \\
\text { - Ease visa issues for foreign employees }\end{array}$ \\
\hline \multirow[t]{2}{*}{ Feasibility } & Low & $\begin{aligned} & \text { - } \text { Creating favourable policy regulation } \\
& \text { (e.g. tax breaks/free-export zones) } \\
& \text { - Good infrastructure for the business } \\
& \text { (e.g. reliable water and electricity } \\
& \text { connection) } \\
& \text { - Reduce corruption } \\
& \text { - } \\
& \text { - Reduce bureaucratic procedures } \\
& \text { Policy focuses on foreign business }\end{aligned}$ & $\begin{array}{l}\text { - Guarantee access to international currency ex- } \\
\text { changes } \\
\text { - Refrain from having a radically religious culture }\end{array}$ \\
\hline & & Low & High \\
\hline
\end{tabular}

\section{Semester 1.}

Ideas for 'what can companies in emerging markets do to expand their business outside their own countries?'

\section{Feasibility}

- Join start up communities

- Hire experts from countries they have interest in

- Start exporting before starting an own

High factory/office abroad

- Marketing

- Send employees abroad for conferences or other forms of training

- Have local partners to facilitate the market entry

- Partner with a foreign firm

- Quality competition

- Invest in a project that will happen in a foreign country

- Go to more corrupt countries and bribe government to allow easy set up 


\section{Semester 2.}

Ideas for 'what can government in emerging markets do to attract new business from abroad?'

- Provide services that support foreign business (e.g. personal and work-related support such as High - Set up business parks to attract
businesses

- Creating favourable policy regulation (e.g. tax breaks/free-export zones)

- Good infrastructure for the business

Feasibility

$\begin{aligned} & \text { (e.g. reliable water and electricity con- } \\ & \text { nection) } \\ - & \text { Reduce corruption } \\ \text { Low }- & \text { Reduce bureaucratic procedures } \\ - & \text { Loosen ethical standards (e.g. be more } \\ & \text { willing to accept bribes from foreign } \\ & \text { firms) } \\ - & \text { Encourage cooperation between com- } \\ & \text { panies and governments (e.g. offer } \\ & \text { partnership programs) } \\ - & \text { Protect the workforce (e.g. safety for } \\ & \text { employees) }\end{aligned}$
(e.g. reliable water and electricity conReduce corruption

- Reduce bureaucratic procedures willing to accept bribes from foreign firms)

Low assistance for expats in housing/schooling and administrative issues)

- Identifying their own local competitive advantage and exploit it (e.g. Southeast Asia can serve as a great logistical hub between Europe/ Japan/rest of Asia and Australia)

- Motivate local business to cooperate or do joint venture

- Give population more liquidity in order to stimulate the own economy in order to attract investments from outside

- Promote the country's assets and/or its natural resources abroad

- Meet and greet between politics and business

- Ease visa issues for foreign employees

- Illustrate possible demand in country

- Host fairs or networking events where governments, business and entrepreneurs can meet each other and promote themselves

Low $\quad$ Originality $\quad$ High

\section{Semester 2.}

Ideas for 'what can companies in emerging markets do to expand their business outside their own countries?'

$$
\begin{aligned}
& - \text { Go to more corrupt countries and bribe } \\
\text { High } & \text { government to allow easy set up } \\
& - \text { Innovation in creating new products } \\
& - \text { Product competition }
\end{aligned}
$$

\section{Feasibility}

$$
\begin{aligned}
- & \text { Partner with a foreign firm } \\
- & \text { Quality competition } \\
\text { Low }- & \text { Get bought by Google or some other } \\
& \text { large company } \\
- & \text { Adapt their own business to foreign } \\
& \text { markets }
\end{aligned}
$$

- Learn from others and copy their ideas

- Outsourcing/offshoring parts of their business

- Creative competition (e.g. cost leadership or differentiation)

- Hire experts from countries they have interest in

- Price competition (i.e. sell at lower cost)

- Marketing

- Marry someone from the other country to get insights into the culture

- Use their cultural background as advantage (e.g. shoes using leather of indigenous people)

- Sell human capital

\section{Low}

Originality

High

Corresponding author at: Kim van Broekhoven, Radboud Teachers Academy, Radboud University, Nijmegen, The Netherlands.

E-mail: kim.vanbroekhoven@docentenacademie.ru.nl

(C) Copyright by Faculty of Education, University of Bialystok, 